Journal of

The Institute

of Brewing

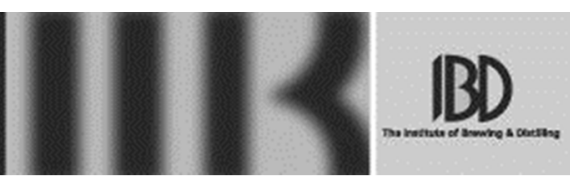

\title{
Draught beer hygiene: cleaning of dispense tap nozzles
}

\begin{tabular}{|c|c|}
\hline Journal: & Journal of the Institute of Brewing \\
\hline Manuscript ID & JIB. 20160460.R1 \\
\hline Wiley - Manuscript type: & Research article \\
\hline Date Submitted by the Author: & $\mathrm{n} / \mathrm{a}$ \\
\hline Complete List of Authors: & $\begin{array}{l}\text { Quain, David; University of Nottingham, International Centre for Brewing } \\
\text { Science }\end{array}$ \\
\hline Keywords: & dispense, beer spoilage, hygiene, tap nozzle, cleaning \\
\hline Abstract: & $\begin{array}{l}\text { Draught beer quality can be compromised by the growth of spoilage } \\
\text { microorganisms. Whilst best practice for assuring dispense hygiene is } \\
\text { broadly recognized, it is not always fully or regularly implemented. In } \\
\text { some markets, tap nozzles are removed and stored overnight at room } \\
\text { temperature in carbonated (soda) water. Next morning they are returned } \\
\text { (sometimes after rinsing) to the dispense tap. The effectiveness of this } \\
\text { approach is compared with soaking in diluted line cleaning solution (UK } \\
\text { best practice) or a solution containing hypochlorous acid (commercial } \\
\text { sanitizing tablets). Two novel approaches - ozonated water and use of } \\
\text { ultrasonics - were also evaluated. Bioluminescence analysis of microbial } \\
\text { attachment to the inner surfaces of nozzles showed that soaking in } \\
\text { carbonated water resulted in gross contamination. Sanitising tablets } \\
\text { achieved 'commercial sterility' and a four-log reduction in microbial loading } \\
\text { compared to carbonated water. The efficacy of hypochlorous acid was } \\
\text { confirmed by incubating cleaned nozzles in fresh beer without any increase } \\
\text { in turbidity. Line cleaning solution was less effective and achieved a two- } \\
\text { log reduction. } \\
\text { Truncated - JIB author guidelines are for an Abstract of } 250 \text { words whereas } \\
\text { here this is restricted to } 200 \text { words! Accordingly the full abstract is } \\
\text { presented in the manuscript. }\end{array}$ \\
\hline
\end{tabular}


Draught beer hygiene: cleaning of dispense tap nozzles

David E. Quain*

* Correspondence to: David Quain, International Center for Brewing Science, School of Biosciences, University of Nottingham, Sutton Bonington Campus, Loughborough, Leicestershire, LE12 5RD, UK.

E-mail: david.quain@nottingham.ac.uk

\begin{abstract}
Draught beer quality can be compromised by the growth of spoilage microorganisms. Whilst best practice for assuring dispense hygiene is broadly recognized, it is not always fully or regularly implemented. In some markets, tap nozzles are removed and stored overnight at room temperature in carbonated (soda) water. Next morning they are returned (sometimes after rinsing) to the dispense tap. The effectiveness of this approach is compared with soaking in diluted line cleaning solution (UK best practice) or a solution containing hypochlorous acid (commercial sanitizing tablets). Two novel approaches - ozonated water and use of ultrasonics - were also evaluated. Bioluminescence analysis of microbial attachment to the inner surfaces of nozzles showed that soaking in carbonated water resulted in gross contamination. Sanitising tablets achieved 'commercial sterility' and a four-log reduction in microbial loading compared to carbonated water. The efficacy of hypochlorous acid was confirmed by incubating cleaned nozzles in fresh beer without any increase in turbidity. Diluted ltine cleaning solution was less effective and achieved a two-log reduction. Ultrasonics reduced microbial attachment but effectiveness was aligned to increasing process time. Soaking in ozonated water was without antimicrobial impact. This work has shown carbonated water to be ineffective in cleaning microbiologically contaminated nozzles., which became progressively contaminated with microbial biofilm. This is a concern as these microorganisms derive from the dispense line, the environment and likely human interaction. To minimize the risks of transfer to dispensed product or back contaminating the dispense line, soaking draught beer nozzles in an effective sanitizing solution is strongly recommended.
\end{abstract}

Keywords: dispense, beer spoilage, hygiene, tap nozzle, cleaning

Short title: cleaning of dispense tap nozzles

Introduction

Globally in 2013, draught beer accounted for 136 million hL per year. Although likely to be a slight underestimate (not all markets are quantified) this represents about $7 \%$ of the total beer market (1). The trade channel for draught beer is the on-trade/on-premise through-comprising of public houses/pubs, bars, events, clubs, restaurants, hotels etc. The added complexity (and cost) of dispense together with ill-defined cultural drivers means that the emphasis on draught beer is globally patchy. That said 
draught beer in some markets is tagged as being 'aspirational' and often anecdotally - in growth (albeit from a small beginnings). In the established on| trade/on-premise accounts typified by the USA, UK, Ireland, Czech Republic and other countries, draught beer volumes are static, in decline or showing signs of slight recovery. (see Fig. 1). For China - the global market leader by volume - draught volumes account for a mere $2 \%$ by volume but equivalent to significant 10.1 million $\mathrm{hL}$ in 2013 (1).

The draught beer market has to contend with a myriad of influencing factors (2). Although invariably weighted differently by time and place, these diverse considerations challenge and potentially erode the category. Whilst price and - off-trade discounting,, smoking ban, drink driving legislation-are eften primary factors, poor and inconsistent product quality is a concern, which is exacerbated where on-trade pricing is high.

Inevitably dispensed beer contains microorganisms. However, draught beer hygiene has received sporadic attention over the years with publications in the 1950's from (what is now) Campden BRI, the now defunct British School of Malting and Brewing at the University of Birmingham (70's and 80's) and occasional papers in the last 20 years or so from the UK, Finland, Germany, USA and Spain (3). Presciently Harper (4) noted in 1981 that 'in view of the large volumes of draught beer served, and the prevalence of microbiological problems, it is surprising to find little published work on the spoilage of beer at the retail outlets'.

The microbiota of draught beer (3) is a diverse mix of yeast species (e.g. Saccharomyces, Brettanomyces, Pichia) and bacteria (e.g. Lactobacillus, Acetobacter, Pediococcus). Management of the loading through hygienic practices and routine, regular line cleaning is key to the assurance of beer quality. Levels of microbial loading in draught beer have been defined within the German DIN standards - 'dispense systems for draught beverages' - but have received little recognition $(3,5)$ within the industry and even less in terms of measurement. DIN 6650 Part 6 (6) refers to a 'typical guideline value for a positive result with respect to microbial contamination would be 1000 colony forming units per milliliter (cfu/ml), a value of more than $50,000 \mathrm{cfu} / \mathrm{ml}$ being considered unacceptable. If the count is 10,000 or higher, cleaning is | necessary'. IAlthough qualitative, these guidelines are in keeping with practical observations for draught beer in Germany, Finland and the UK (3). Indeed a hitherto unpublished survey (D.E. Quain) of the same brand | sampled in 12 accounts (Table 1), shows thatsuggests six accounts required line cleaning and quantitatively aerobic microorganisms are typically more plentiful than anaerobes in dispensed beer.

Microorganisms 'do not live solitary lives' (7). In 'virtually all natural and pathogenic ecosystems' (8) microorganisms are found in mixed-species, multicellular biofilms attached to surfaces. These communities are as diverse as the environments in which they are found. Although predominately water, the 'cement' for the intraspecies and interspecies microbial communities are diverse extracellular polymeric material (predominately protein and polysaccharides) secreted by the cells within the biofilm. This gel-like matrix 
varies in density with channels for circulating nutrients and removing byproducts (9). As is well recognized, the sessile cells within biofilms are markedly more difficult to kill as the polymeric matrix provides physical protection to anti-microbial agents. Further sessile cell physiology may be less susceptible in being slow growing, senescent or having a 'biofilm phenotype' (10). As the sessile biofilm communities mature, non-sessile 'planktonic' microorganisms are dispersed to attach to new surfaces and initiate new biofilms. This and other events in the biofilm life cycle are orchestrated by cell-to-cell communication or quorum sensing that drives selforganization, regulation and cooperation within biofilms. Bacteria (and yeast) produce a diffusible organic signal or autoinducer, which accumulates in the environment and triggers a spectrum of events such as gene expression or behavioral adaptation. There are a host of diverse signaling molecules used by bacteria including oligopeptides (Gram-positive bacteria), and acyl homoserine lactones (Gram-negative bacteria) (11). With yeast, the pathogen Candida albicans uses farnesol and tyrosol for quorum sensing, whereas with Saccharomyces cerevisiae signaling molecules include 2-phenylethanol, tryptophol, and tyrosol (7).

The role of biofilms and associated threat to product and process hygiene in brewing, owe much to the work of Storgårds and her colleagues over the last 20 years at VTT Technical Research Centre in Finland (e.g.12). In addition to reviews (13-15) there is growing interest and awareness of biofilms in packaging operations $(12,16)$ and on surfaces across a microbrewery $(17)$. Further, signaling via acyl homoserine lactones has been demonstrated in bacteria colonizing brewery process surfaces (18).

Ironically, although not flagged specifically as biofilm, a number of reports from the British School of Malting and Brewing refer to the presence of microorganisms in the 'lumen' of the beer dispense line where they 'adhere', 'stick' and 'proliferate' (4, 19-21). Indeed, Casson's 1985 paper (22) contains an electron micrograph in keeping with contemporary biofilm images of 'contaminated dispense piping' revealing 'many layers of cells adhered to the internal surface'. The impact of different line materials (e.g. mid-density polythene, nylon and polyvinyl chloride) to microbial attachment was also investigated $(21,23)$. Tellingly the line-cleaning regime detailed in 1976 (19) remains the approach mostly used predominately today.

Cleaning of dispense lines with typically cold sodium (or potassium) hydroxide based cleaning solutions is generally effective at removing biofilms attached to the surface of the tubing (3). Best practice varies for cleaning frequency around the world reflecting differing complexity, cellar temperatures, distance (between keg and tap) and dispense temperature. Regrettably, whatever the required frequency, 'line cleaning' can be missed and deferred for a host of diverse reasons. This is of course-a false economy that results in increasingly compromised product quality and hygienically, a dispense system that is harder to clean effectively. Repeated slippage can leads to a vicious circle where product quality spirals down which, depending on the consumer reaction, can underminetogether - most likely - with the profitability of the account. Accordingly, the trend to third-party contracted-out line cleaning 
services is-would be expectedanticipated to improve the robustness and regularity of the process.

TClearly the need for regular line cleaning indicates that the system end to end is not completely clean such that inevitably recontamination reoccurs (3). Candidates for the source of reinfection this-include fob detectors together with connectors and various fittings. In addition microbiological contamination enters the dispense system via other routes such as the unhygienic handling of container coupler and connection or, the indigenously low levels of microorganisms in chilled and filtered beer (more so in cask beer). Arguably though these routes pale into insignificance compared to the unhygienic handling of tap nozzles or spouts.

In some markets, 'nozzles' are integral to the design of the dispense tap and cannot be removed. Accordingly on cleaning the beer dispense line the | nozzles are-also cleaned in situ. In the UK and elsewhere, a high proportion of tap nozzles are removable through design or because of the inclusion of orifice plates/diffusers that are required to be cleaned separately. Best | practice for the cleaning of nozzles is at bestconfused. In the UK, the long running 'Profit Through Quality Handbook' (24) from the British Institute of Innkeeping was updated in 2011 to 'remove orifice plates and nozzles from taps (where fitted) everyday, clean thoroughly with an appropriate, nontainting sanitiser and rinse well in fresh water'. The extent of take-up of this is not clear but anecdotally appears to be slight. Indeed, some years earlier the British Beer and Pub Association (BBPA) (25) recommended that nozzles should be removed at the end of the trading day and soaked in dispense line cleaner. Not surprisingly as line cleaner is elsewhere in the cellar (i.e. not close by) and perhaps because of health and safety concerns, soaking in line cleaner is - at best - rare. Reportedly (26), some accounts soak nozzles in hot water from the cafeteria and air-dry overnight, some cycle through the glass washer but - for reasons that are difficult to explain - the received wisdom across the on-trade in the UK is to soak nozzles overnight on the 'back bar' in carbonated/soda water. Anecdotally, soda water is reported by users to be superior in its antimicrobial effect than tap water! That said frequent observation of cloudy, beery soups in pint glasses undermines the argument that soda water in effective in managing the hygiene of nozzles.rather challenges the validity of the approach.

Only a handful of publications have focused on the dispense tap as a contributor to contamination of draught beer $(19,20,27,28)$. Two publications $(3,13)$ have drawn particular attention to tap nozzle hygiene and have flagged concerns about the efficacy of soaking overnight in soda water.

The work reported here evaluates the effectiveness of different approaches to cleaning dispense nozzles contaminated with microorganisms originally recovered from trade samples. These include soaking in soda water, ozonated water, diluted line cleaning solution and commercial sanitizing tablets dissolved in water. The application of ultrasonics to remove microbial contaminants was also assessed alone and in conjunction with soda water 
and ozonated water. The impact of the treatments was assessed indirectly using ATP bioluminescence and directly by 'forcing' nozzles in fresh beer.

\section{Materials and methods}

\section{Technique}

All transfers, additions or manipulations were performed aseptically.

\section{Nozzles}

Black plastic 100/34 lager nozzles (5.8 cm long) were supplied by England Worthside Ltd, Keighley, West Yorkshire, BD21 5LJ.

\section{Experimental oMicrobial soups-overview}

Three experiments were performed with contaminated nozzles cycled between commercial beer (ex can) and a cleaning approach. A comparative overview of the preparation of the microbial soup, cleaning treatments and analysis is presented in Table 2.The microbiology of the three experiments 'evolved' from predominately free, planktonic cells in dispensed beer through a mix of planktonic and attached sessile biofilm to fully sessile. It would be anticipated that cleaning became more challenging with the sessile microbial soup.

Microbial soup (1) - 'planktonic'

Ten draught beers was-were sampled $(25 \mathrm{ml})$ from four local public houses representing nine brands of which three were cask ale beers, four lager and two stout. The samples were bulked together and incubated at $30^{\circ} \mathrm{C}$ with the addition of $1 \mathrm{ml}$ glucose $(30 \%, \mathrm{w} / \mathrm{v})$ after $24 \mathrm{~h}$ and $5 \mathrm{ml}$ after 4 days. After 5 days the culture was extended to $600 \mathrm{ml}$ by the addition of lager ( $5 \% \mathrm{abv}$ ) and incubated for a further two days at $30^{\circ} \mathrm{C}$. After a further two days of incubation the culture was split into $2 \times 300 \mathrm{ml}$ and autoclaved dispense nozzles (16) added to each culture. After 5 days incubation at $30^{\circ} \mathrm{C}$, six nozzles were added alternately to 4 × 250 Duran bottles each containing 200 $\mathrm{ml}$ lager ( $5 \% \mathrm{abv})$.

\section{Experiment 1}

Batches of six nozzles were cycled for six days between 12 hours incubation in $200 \mathrm{ml}$ fresh lager beer $(4 \% \mathrm{abv})$ at $30^{\circ} \mathrm{C}$ and, after draining, four different putative cleaning methods (detailed below) for 12 hours and at $30^{\circ} \mathrm{C}$.

- Soaked in $200 \mathrm{ml}$ soda water (containing carbonated water, sodium carbonate).

- Soaked in ozonated water containing $4 \mathrm{mg} / \mathrm{L}$ ozone.

- Sonicated in $1 \mathrm{~L}$ tap water (1 min), drained and soaked in soda water.

- Sonicated in $1 \mathrm{~L}$ tap water (1 $\mathrm{min})$ drained and soaked in ozonated water.

The ozonated water was generated from a Biolux iEOG Hydrogen and Ozonated Water System. The ultrasonic bath had a capacity of $3.2 \mathrm{~L}$, a frequency of $40 \mathrm{kHz}$ and a power rating of $120 \mathrm{~W}$. 
As detailed below, for each treatment, the hygiene of five nozzles was assessed using ATP bioluminescence and one nozzle by forcing.

\section{Microbial soup 2 - 'planktonic and sessile'}

The inoculum was a mix of the above microbial soup $(10 \mathrm{ml})$ and nozzle forcing's (see below) derived from each of the above four treatments $(4 \times 10$ $\mathrm{ml}$ ). This was extended with $440 \mathrm{ml} 4 \%$ abv lager and $5 \mathrm{ml} \mathrm{30 \% (w/v)} \mathrm{glucose}$ and incubated at $30^{\circ} \mathrm{C}$. After two days the culture was divided into $2 \times 500 \mathrm{ml}$ Duran bottles and topped up to ' $500 \mathrm{ml}$ ' with $4 \%$ abv lager. After a further three days at $30^{\circ} \mathrm{C}, 42$ nozzles (soaked overnight in 1/60 line cleaning solution and rinsed with water) were added to each culture together with an additional $5 \mathrm{ml} 10 \%(\mathrm{w} / \mathrm{v})$ glucose. After seven days incubation, the nozzles were removed aseptically and transferred $(2 \times 21)$ to fresh lager $(4 \%$ abv $)(2 \times$ $440 \mathrm{ml}$ ). After two days incubation at $30^{\circ} \mathrm{C}$, six nozzles were added alternately to $7 \times 250 \mathrm{ml}$ Duran bottles each containing $200 \mathrm{ml}$ lager (4\% abv).

\section{Experiment 2}

Batches of six nozzles were cycled for seven days between 12 hours incubation in $200 \mathrm{ml}$ fresh lager beer $\left(4 \%\right.$ abv) at $30^{\circ} \mathrm{C}$ and, after draining, seven different putative cleaning methods (detailed below) for 12 hours and at $30^{\circ} \mathrm{C}$.

- Soaked in $200 \mathrm{ml}$ soda water.

- Soaked in $500 \mathrm{ml}$ diluted alkaline line cleaning solution for 12 hours, drained and rinsed in an equivalent volume of tap water.

- Soaked in $500 \mathrm{ml}$ 'sanitising' solution for 12 hours, drained and rinsed in an equivalent volume of tap water.

- Sonicated in $1 \mathrm{~L}$ tap water (0.5 min), draining-drained and incubating incubated aseptically 'dry' in a 250 Duran bottle.

- Sonicated in $1 \mathrm{~L}$ tap water $(1 \mathrm{~min})$ and treated as above.

- Sonicated in $1 \mathrm{~L}$ tap water (2 min) and treated as above.

- Sonicated in $1 \mathrm{~L}$ tap water (5 $\mathrm{min}$ ) and treated as above.

As detailed below, for each treatment, the hygiene of five nozzles was assessed using ATP bioluminescence and one nozzle by forcing.

The dispense line cleaning solution - Pipeline Original (diluted 1/60) - and sanitizing tablets for nozzles (active ingredient troclosene sodium or sodium dichlorisocyanurate) were obtained from Chemisphere UK Ltd, Unit 4, No 3 Richmond Road, Trafford Park, Manchester, M17 1RE.

\section{Microbial soup 3- 'sessile'}

The inoculum was sourced from the forcing samples from the 'experiment 2' experiment and was therefore-presumably enriched in microorganisms associated with the surfaces of contaminated nozzles. The samples ex forcing $(140 \mathrm{ml})$ were derived from $20 \mathrm{ml}$ of each of the seven treatments above, of which $50 \mathrm{ml}$ was extended with $440 \mathrm{ml} 4 \%$ abv lager and $5 \mathrm{ml} \mathrm{30 \%}$ $(\mathrm{w} / \mathrm{v})$ glucose and incubated at $30^{\circ} \mathrm{C}$. After two days the culture was divided into $2 \times 500 \mathrm{ml}$ Duran bottles and topped up to ' $500 \mathrm{ml}$ ' with $4 \%$ abv lager. After a further three days at $30^{\circ} \mathrm{C}, 21$ nozzles (soaked for 24 hours in $1 / 60$ 
line cleaning solution and rinsed three times with water) were added to each culture together with an additional $5 \mathrm{ml} \mathrm{30 \% (w/v)} \mathrm{glucose.} \mathrm{After} \mathrm{seven} \mathrm{days}$ incubation, the nozzles were removed aseptically and transferred $(2 \times 21)$ to fresh lager $(4 \%$ abv $)(2 \times 440 \mathrm{ml})$. After two days incubation at $30^{\circ} \mathrm{C}$, six nozzles were added alternately to $6 \times 250 \mathrm{ml}$ Duran bottles each containing $200 \mathrm{ml}$ lager (4\% abv). The hygiene of two nozzles from the soup was assessed (using ATP bioluminescence) to establish the extent of contamination at the outset of the experiment.

\section{Experiment 3}

Nozzles (12) in two batches of six were cycled for seven days between 12 hours incubation in $200 \mathrm{ml}$ fresh lager beer $(4 \% \mathrm{abv})$ at $30^{\circ} \mathrm{C}$ and, after draining, three different putative cleaning methods (detailed below) for 12 hours and at $30^{\circ} \mathrm{C}$.

- Soaked in $500 \mathrm{ml}$ soda water, drained and rinsed in an equivalent volume of tap water.

- Soaked in $500 \mathrm{ml}$ diluted alkaline line cleaning solution for 12 hours, drained and rinsed in an equivalent volume of tap water.

- Soaked in $500 \mathrm{ml}$ 'sanitising' solution, drained and rinsed in an equivalent volume of tap water.

As detailed below, for each treatment, the hygiene of six nozzles was assessed using ATP bioluminescence and by forcing in fresh beer at $30^{\circ} \mathrm{C}$.

\section{Analysis}

\section{Bioluminescence}

The hygiene of the internal surface of nozzles was measured using ATP bioluminescence with Clean-Trace ${ }^{\mathrm{TM}}$ swabs from $3 \mathrm{M}$. Post treatment, nozzles were drained (ex soda water, line cleaner, sanitizing tablets), rinsed with an equivalent volumein $200 \mathrm{ml}$ of sterile deionised tap-water or analyzed as is (ex ultrasonics). Rinsed nNozzles were removed, placed upright on a paper towel, processed individually and after immersion in sterile water (150 $\mathrm{mll}$ ), were-marked with a spot (white correction fluid) and the internal surface swabbed vertically at four locations (north, south, west and east). Accordingly four measurements were made per nozzle with five (treatments-experiments 1 and 2) or six (treatment experiment 3) nozzles per treatment being analysed. ATP as (relative light units or RLU's) was determined using a 3M NG bioluminometer. The highest RLU's observed were ca. 1,000,000 with the maximum RLU for the instrument being 9,999,999. No attempt was made to correlate RLU's with microbiological plate counts as this is subject to numerous caveats and complications ( 32 and see below)

\section{Forcing}

A more direct and all embracing approach to surface hygiene was to 'force' nozzles post treatment by incubation in beer (lager, $4 \%$ abv) at $30^{\circ} \mathrm{C}$. The progress of microbial infection was assessed either qualitatively (experiments 1 and 2, visually) or quantitatively (experiment 3 ) against time at $660 \mathrm{~nm}$ using a WPA S2100 Biowave spectrophotometer.

Formatted: Font: Italic 


\section{Results and discussion}

The three experiments reported here have a common approach. Clean Sterile dispense nozzles were initially contaminated with microorganisms originally sourced from commercial samples of draught beer. After incubation | in this 'microbial soup', the nozzles were soaked for (up to seven) cycles of 12 hours in beer and soaked (or treated) for 12 hours in a putative cleaning | solution (see Table 2). for up to seven days.

The effectiveness of various cleaning approaches was determined using ATP bioluminescence; a real time technology used widely to assess hygiene in the brewing and food industries (29-31) - including draught beer dispense $(27,28)$ - and increasingly in healthcare $(32,33)$. Undeniably an innovation in microbiological monitoring, the technology measures ATP, the energy molecule found in living microorganisms, dead microorganisms and the 'environment' (33). The relationship between ATP and conventional microbial counts is at best 'directional' (32) reflecting a host of considerations including cellular ATP content (yeast v bacteria, growth conditions, stress, turnover etc) and accuracy of plate counts (selective media, non-culturability, homogeneity of sampling etc.) To add further complexity there are also reports of ATP efflux from yeast where it has been implicated in signaling (34) and Gram| positive and Gram-negative bacteria linked to active growth (35). Whatever, ATP bioluminescence has transformed hygiene quality assurance and is integral to real-time monitoring of cleaning in place (CiP) via testing of surfaces or rinses.

As described above, at the beginning of each experiment, clean sterile nozzles were immersed in a microbial soup so as to grow a biofilm on the internal (and external) surfaces. Over the course of the three experiments, the 'soup' evolved from predominately planktonic (free flowing, unattached microorganisms) ex dispense in the initial experiment through a mix of planktonic and sessile (surface attached) to predominately sessile in experiment 3. Over the course of the three experiments (Table 3 ) This reflected in the average bioluminescence value (RLU) for nozzles soaked in the 'control' soda water (Table 2) increased from 250,796 (experiment 1, $\mathrm{n}=$ 20 ) to 636,720 (experiment $2, n=20$ ) to $1,114,165$ (experiment $3, n=24$ ). It is suggested that the increase in RLU reflects the selection of more sessile microorganisms from the microbial soup ex dispense in the initial experiment to predominately sessile from nozzle forcings in experiment 3.

The aim of this work was to compare and contrast nozzle cleaning after repeated soaking in soda water - the de facto industry standard - and other treatments such as the recommended line cleaning solution, commercial sanitising tablets and novel approaches such as ozonated water, ultrasonics or both in combination.

\section{Experiment 1. Ozone and ultrasound - alone and together}

Ozone is an oxidizing agent that rapidly inactivates a wide spectrum of microorganisms in aqueous liquids and accordingly, as long ago as 1907, has been used to disinfect drinking water. Its oxidation potential is less than 
fluorine but greater than chlorine dioxide and hypochlorous acid. However it is unstable and requires to be generated at the point of use as it decomposes quickly (to oxygen and free radicals) but importantly leaves no residue or byproducts (36). In the food industry, ozone has found application as a sanitizer/disinfectant post cleaning with an alkaline or dilute acid detergent (37). With brewing, ozone has garnered little interest other than ${ }_{2}-$ pertinently $y_{2}-$-a study of the use of ozonated water to clean draught beer dispense lines. This work with a model system (38), showed ozonated water to be as (or more) effective than a commercial line cleaning solution in the removal of biofilm from the dispense line.

Ultrasound has long been used via ultrasonic 'baths' to clean a variety of objects (e.g. jewelry, dental and surgical instruments etc.) The use of ultrasound to remove microbial biofilms on surfaces has something of a mixed press. A somewhat confused literature reports that ultrasound can both be effective against biofilms but can also enhance bacterial viability (39). As ever in microbiology this may be explained by - amongst other factors - differences in frequency and intensity of the ultrasound, the diversity of microbial species and their physiology. More generically, ultrasound (frequencies $>20 \mathrm{kHz}$ ) has found increasing interest and application for process innovation in the food industry (40). Applications in the brewing industry have been low key with small-scale studies on using ultrasonics to reduce foam formation in fermenter (41), removal of mixed biofilm from stainless steel (42), increasing ethanol formation during fermentation (43) and accelerating and enhancing the germination of barley (44).

The possible application of ozone, ultrasound or both technologies in cleaning contaminated dispense nozzles was evaluated against soaking in soda water. In all six cycles were performed, alternating soaking contaminated nozzles in beer for 12 hours followed by removal and treatment (soaking or ultrasonics with draining and storing dry but sterile) for 12 hours.

Although widely used across the UK on-trade, soaking contaminated nozzles in soda water did not clean them but resulted in heavily contaminated nozzles as measured by ATP bioluminescence(Fig. 1). This is not surprising, as despite custom and practice, carbonated water would not be anticipated to either kill microorganisms or (without any mechanical action) remove biofilm from surfaces. Ozonated water was without effect with ATP measurements of the nozzles comparable to soda water. Given ozone's role in sanitization in the food industry (37) this was unexpected but may reflect ozone's rapid decomposition in water to oxygen (36) thereby limiting any impact to the biofilm during exposure.

However, ultrasonic treatment for one minute with either tap or ozonated water had a significant effect on nozzle hygiene achieving a three-log reduction in loading compared to the loading in soda water (Fig. 1, Table ZTable 3 ). Indeed, in the context of validation of brewery $\mathrm{CiP}$, the results for either ultrasonic treatment would constitute a 'pass' against the wellestablished Clean-Trace ${ }^{\mathrm{TM}}$ guidelines for ATP bioluminescence of pass $(<150$ RLU), caution (150-299 RLU) and fail (>300 RLU) (30). This observation was 
borne out qualitatively by 'forcing' (in beer) two nozzles post ultrasonic treatment and two after soaking in soda water. The beer containing nozzles post ultrasonic treatment remained bright for four days whereas the beer with nozzles from soda water became cloudy within a day or so.

\section{Experiment 2. Ultrasound, line cleaning solution and sanitizing tablets} An ultrasonic bath could provide an affordable and simple approach to cleaning removable nozzles. However, as performed here, the nozzles would be removed post treatment and stored dry (overnight) until being returned to the dispense tap. Building on the above work, clean nozzles were incubated in a fresh microbial soup enriched with sessile microorganisms recovered from the above nozzle forcings. It was anticipated that this source of | microorganisms would encourage the growth of a more substantive biofilm on the nozzle surfaces. Accordingly, the efficacy of ultrasonic cleaning was evaluated against time and again compared with soaking in soda water. In addition two further treatments were included: soaking in line cleaning solution (as recommended by the BBPA - 25) and soaking in solution with commercial nozzle 'sanitising' tablets.

In this experiment, the cycles of soaking in beer and soaking/treatment were increased to seven days. Nozzles soaked in soda water were again heavily

| contaminated (Fig.23), with ATP bioluminescence readings 2.5 -fold greater than the first experiment. This perhaps reflects the loading and enrichment with sessile microorganisms. Indeed, the suggestion that the biofilm was more challenging to remove was supported by ultrasound treatment being less effective, requiring treatment for five minutes to achieve a three-log | reduction in RLU readings (Table 2Table 3 ).

Although recommended for soaking nozzles, a commercial line cleaning solution - containing potassium hydroxide, sodium hypochlorite and sodium carbonate - achieved mixed success achieving a two-log reduction in | microbial loading compared to soda water (Table 3). This may be a consequence of the formulation and lack of 'mechanical action', which is a key parameter to the effectiveness of caustic detergents in CiP operations (13). Further, ${ }_{2}$ poor 'wettability' was observed on removing nozzles from soaking in line cleaning solution. This may have undermined universal penetration into the biofilm.

In terms of average bioluminescence readings (Table 2Table 3 ), both ultrasonics for five minutes or soaking in line cleaning solution failed to | achieve the Clean-Trace ${ }^{\mathrm{TM}}$ bioluminescence guidelines for successful CiP. More successful - although average RLU was still (just) a fail - was soaking | nozzles in a solution containing dissolvedfrom commercially sourced sanitizing tablets. The active agent sodium dichlorisocyanurate, which is used widely in water purification, achieved a three-log reduction in | bioluminescence. Once again, the -forcing approach (data not shown) confirmed the comparative cleanliness of nozzles soaked with sanitizing tablets, which remained bright for nine days. All other treatments became progressively more turbid after 24-36 hours of incubation. 
Experiment 3. Sanitizing tablets - best practice for cleaning nozzles? The microbial soup for this experiment was sourced solely from the nozzle 'forcings' in the previous experiment and would-might therefore be expected to be well adapted to attach to nozzle surfaces. Indeed, nozzles soaked in soda water were very heavily contaminated (Fig. 34 ), with ATP

bioluminescence readings 1.8 -fold greater than the second experiment and 4.4-fold the first experiment. Swab analysis of sacrificial nozzles from the microbial soup suggests significant further attachment during cycling between beer and soda water such that bioluminescence (RLU) increased from $166,065 \pm 33,230(n=8)$ ex-soup to $1,114,165 \pm 15,071(n=24)$ at the end of the experiment.

In keeping with anticipated greater microbial challenge, the bioluminescence readings for nozzles 'cleaned' in soda water were the highest observed with in excess of a million RLU. Line cleaning solution was less effective than in the previous experiment, achieving a two-log reduction in RLU compared to soda water (Fig.3, Fig. 1, Table 2Table 3). Solutions containing a sSanitizing tablets were most effective, with RLU within the Clean-Trace ${ }^{\mathrm{TM}}$ bioluminescence guidelines for successful CiP together with a four-log reduction in RLU. A Student's t-test (2-tailed) showed that the RLU for treatment with sanitizing tablets was significantly lower than with line cleaning solution $(P<0.05)$. For a clearer comparison of this data, Fig 4 represents Fig. 3 with data plotted 'as is' rather than logarithmically.

Whilst bioluminescence provides a general measure of nozzle hygiene, viable organisms can be assessed by the incubation of nozzles in fresh beer and measurement of turbidity over time. The data presented in Figs 5a-c for forcing (in triplicate) of twosix nozzles per treatment (three batches of two nozzles) per treatment is in good agreement with the bioluminescence results shown in Fig $\underline{34}$. The heavy and viable contamination of nozzles cycled through soda water is apparent from the increase in turbidity within 24 hours (Fig.5a). With line cleaning solution there was a lag of three days before turbidity increased markedly (Fig.5b). Beer containing nozzles treated with sanitizing tablets were - in terms of bioluminescence - 'clean', remained bright without any appreciable increase in turbidity over 19 days of incubation at $30^{\circ} \mathrm{C}$ (Fig.5c).

The forcing approach reinforced the general conclusions from bioluminescence testing with the added insight that the microorganisms attached to the nozzle surface were sufficiently viableable to rapidly spoil beer. The noise - notably with soda water (Fig. 5a) - can be explained from the reattachment of microorganisms to surfaces and incomplete removal by mixing to the supernatant before sampling. It is noteworthy that the turbidity was greater with nozzles treated with line cleaning solution compared to soda water. This may be explained by the-microscopy (data not shown), where the soda water forcing containeding a mix of bacteria (short rods) and yeast whereas with the forcing of nozzles after treatment with line cleaning solution, only yeast was observed. In this case the available nutrients are utilized by yeasts which, being bigger cells, result in greater turbidity. 
The commercial sanitizing tablets were used as recommended by dissolving a tablet $(0.35 \mathrm{~g} 350 \mathrm{mg})$ in a pint of water. This approach was uniformly effective in managing microbial contamination as demonstrated by the low RLU of swabs of the internal surfaces of the nozzles (Fig.3) and no spoilage of beer on incubation of treated nozzles (Fig. $5 \mathrm{c}$ ). The active ingredient in the effervescent (self-dissolving) tablets is sodium 3,5-dichloro-2,4,6-trioxo-1,3,5triazinan-1-ide better known as sodium troclosene or sodium dichloroisocyanurate which is used as an alternative to sodium hypochlorite in treating contaminated water.

The excellent review by Clasen \& Edmondson (45) notes that the use of sodium dichloroisocyanurate (NaDCC) in water purification has been approved by the World Health Organization for the emergency treatment of water and by the US Environmental Protection Agency for routine treatment of water. In addition to drinking water, NaDCC has also found application in swimming pools, cooling towers, baby's bottles and contact lens. Like sodium hypochlorite, NaDCC releases free available chlorine (FAC) as hypochlorous acid in water. Unlike sodium hypochlorite, NaDCC releases about $50 \%$ FAC with the remainder bound as 'reservoir chlorine' as chlorinated isocyanurates. As the FAC is depleted, the bound 'reservoir' compensates by releasing further hypochlorous acid until it all used up. It would be anticipated that this 'topping up' would enhance the effectiveness of NaDCC as an anti-microbial.

These results suggest that sanitizing tablets containing NaDCC successfully | remove biofilm-microorganisms on nozzles and achieve 'commercial sterility'. Whatever the source, hypochlorous acid is the go to biocide for treating water distribution systems and specifically the management of Legionella biofilms (46). As would be expected, sessile cells within the biofilm are notably harder to kill with hypochlorous acid than planktonic cells (46). However, hypochlorous acid is reportedly effective at removing the extracellular polymeric material in some biofilms, which aids penetration and access to kill microorganisms (46). Building on this, there is evidence (47) that NaDCC is effective against both planktonic and sessile cells of Pseudomonas aeruginosa. Similarly NaDCC has been shown to be effective at killing biofilms of Salmonella Typhimurium grown on coupons of stainless steel with different finishes and roughness (48). The work reported here is further evidence of the efficacy of NaDCC against biofilms and in the form of sanitizing tablets can be recommended as being effective for assuring the hygiene of dispense nozzles.

\section{Conclusions}

Quality is an important Consumer expectation. However, the quality of draught beer is variable, all too frequently exhibiting faults in clarity, taste or aroma. Such issues usually reflect the presence of spoilage microorganisms, the loading of which are managed through hygienic practices and processes. The dispense tap is a primary contender for contamination which is exacerbated where removable nozzles are soaked daily in carbonated (soda) water overnight. 
This work has shown that 'cleaning' with soda water is an urban myth and, as a de facto industry standard, results in grossly contaminated nozzles. On commencement of trading and return to the tap, infected nozzles would be anticipated to contaminate the dispense system. However, in the 'real world', the situation is likely to be of even greater concern as this work has not factored-in considerations such as cross contamination (e.g. soft drink dispenser), the environment or bar staff handling post catering, cleaning and general handling (glassware, money and surfaces).

Assurance of nozzle hygiene is achieved by soaking in a solution containing hypochlorous acid from commercially available sodium dichloroisocyanurate sanitizing tablets. The approach is effective in achieving 'commercial sterility' and is convenient, cheap and, from this work, recommended. Line cleaning solution whilst UK best practice, was found to be less effective perhaps reflecting the formulation_or the lack of mechanical actionand incomplete wettability.. Novel approaches were either without effect (ozonated water) or were inconsistent (ultrasound).

\section{Acknowledgements}

Many thanks to Howard Marles from Aquazone Ltd/Custom Laboratory Products Ltd for stimulating this work and Dr. Martin Walker for rejuvinatingrejuvenating a wider programme of research into dispense hygiene. Similarly big thanks to Gareth Lang of $3 \mathrm{M}$ for his long-term support and supply of Clean-Trace ${ }^{\mathrm{TM}}$ ATP swabs. The three referees of this paper are thanked for their comments and suggestions to improve the manuscript. Support from red-ts Ltd is also gratefully acknowledged.

\section{References}

1. British Beer and Pub Association. (2015) Statistical Handbook (Tettenborn, M. Ed), Brewing Publications Ltd, London.

2. Quain, D. (2007) Draught beer quality - challenges and opportunities. Proc. Eur. Brew. Conv. Congr. Venice, Fachverlag Hans Carl, Nürnberg, pp. 791-801.

3. Quain, D.E. (2015) Assuring the microbiological quality of draught beer, in Brewing Microbiology - Managing Microbes, Ensuring Quality and Valorising Waste (Hill, A. Ed.) pp 333-352, Woodhead Publishing, Cambridge.

4. Harper, D.R. (1981) A microbiologist looks at beer dispense. Brew. Guard. August, 23-28, 31.

5. Jurado, J. (2003) Hygienic design, installation, and maintenance standards for draft beer dispense: German progress and North America's challenge. Tech. Q. Master Brew. Assoc. Am. 40, 271-279.

6. Anonymous. (2006) DIN 6650-6 Dispense systems for draught beverages - Part 6: Requirements for cleaning and disinfection.

7. Avbelj, M., Zupan, J., Kranjc, L and Raspor, P. (2015) Quorum-sensing kinetics in Saccharomyces cerevisiae: A symphony of ARO genes and aromatic alcohols. J. Agric. Food Chem. 63, 8544-8550.

8. Costerton, J.W. (2004) A short history of the development of the biofilm concept, in Microbial Biofilms (Ghannoum, M and O'Toole, G.A. Eds.) pp 4-19, ASM Press, Washington, DC. 
9. Davey, M.E and O'Toole, G.A. (2000) Microbial biofilms: from ecology to molecular genetics. Microbiol. Mol. Biol. R. 64, 847-867.

10. Costerton,J.W., Stewart, P.S and Greenberg, E.P. (1999) Bacterial biofilms: A common cause of persistent infections. Science. 284, 13181322.

11. Simões, M., Simões, L and Vieira, M.J. (2010) A review of current and emergent biofilm control strategies. Food. Sci. Technol-LEB. 43, 573-583.

12.Priha, O., Raulio, M., Cooke, K., Fisher, L., Hill, C., Hylkinen, S., Kelly, P., Navabpour, P., Ostovarpour, S., Tapani, K., Tattershall, C., Vehviläinen, A-K., Verran, J and Storgårds, E. (2015) Microbial populations on brewery filling hall surfaces - progress towards functional coatings. Food Control. 55, 1-11.

13. Boulton, C and Quain, D. (2001) Brewing Yeast and Fermentation, Blackwell Science, Oxford.

14. Quain, D and Storgårds, E. (2009) The extraordinary world of biofilms. Brew. Dist. Int. 5, 31-33.

15. Mamvura, T.A., lyuke, S.E., Cluett, J.D and Paterson, A.E. (2011) Soil Films in the Beverage Industry: A Review. J. Inst. Brew. 117, 608-616.

16. Timke, M., Wang-Lieu, N.Q., Altendorf, K and Lipski, A. (2008) Indentity Identity, beer spoiling and biofilm forming potential of yeasts from beer bottling plant associated biofilms. Antonie van Leeuwenhoek. 93, 151-161.

17. Maifreni, M., Frigo, F., Bartrolomeoli, I., Buiatti, S., Picon, S and Marino, M. (2015) Bacterial biofilm as a possible source of contamination in the microbrewery environment. Food Control. 50, 808814.

18. Priha, O., Juvonen, R., Tapani, K and Storgårds, E. (2011) Acyl homoserine lactone production by brewery process surface bacteria. J. Inst. Brew. 117, 182-187.

19. Hough, J.S., Young, T.W., Braund, A.M., Longstaff, D., Weeks, R.J and White, M.A. (1976) Keg and cellar tank beer in public houses - a microbiological survey. The Brewer. June, 179-183.

20. Harper, D.R., Hough, J.S and Young, T.W. (1980) Microbiology of beer dispensing systems. Brew. Guard. January, 24-28.

21. Casson, D. (1982) Beer dispense lines. The Brewer. November, 447453.

22. Casson, D. (1985) MicrobiologigalMicrobiological problems of beer dispense. The Brewer. November, 417-421.

23. Thomas, $\mathrm{K}$ and Whitham, $\mathrm{H}$. (1996) Improvement in beer line technology. Eur. Brew. Con. Monograph XXV, Fachverlag Hans Carl Edinburgh, 124-138.

24. British Institute of Innkeeping Awarding Body. https://biiab.bii.org/documents/618 (accessed 28th November 2015).

25. Long, D.E. (2003) Hygienic management of cellars and cleaning of beer dispense lines. British Beer and Pub Association. Technical Circular No. 379.

26. Board, C. (2010) A study of hygiene practice regarding beer dispense tap nozzles. http://www.bar-tech.co.uk/wp- 
content/uploads/2012/11/Charles-Board-Nozzle-Thesis.pdf [accessed 13th December 2015].

27. Orive i Camprubi, M. (1996) Hygiene monitoring in draught beer dispensers. Eur. Brew. Con. Monograph XXV, Fachverlag Hans Carl Edinburgh, 173-185.

28. Storgårds, E and Haikara, A. (1996) ATP bioluminescence in the hygiene control of draught beer. Ferment. 9, 352-360.

29. Ogden, K. (1993) Practical experiences of hygiene control using ATPbioluminescence. J. Inst. Brew. 99, 389-393.

30. Quain, D.E. (1999) The '"new'"- microbiology. Proc. Eur. Brew. Conv. Congr. Cannes, IRL Press, Oxford, pp. 239-248.

31. Boulton, C. (2012) Advances in analytical methodology in brewing. J. Inst. Brew. 118, 255-263.

32. Shama, G and Malik, D.J. (2013) The uses and abuses of rapid bioluminescence-based ATP assays, Int. J. Hyg. Envir. Heal. 216, 115125.

33. Alfa, M.J., Olsen, N and Murray, B-L. (2015) Adenosine tri-phosphate (ATP)-based cleaning monitoring in health care: how rapidly does environmental ATP deteriorate? J. Hosp. Infect. 90, 59-65.

34.Peters, T.W., Mileer, A.W., Toutette, C., Agre, H., Hubbard, A and Hughes, R.E. (2016) Genomic analysis of ATP efflux in Saccharomyces cerevisiae. G3. 6, 161-170.

35. Mempin, R., Tran, H., Chen, C., Gong, H., Kim Ho, K and Lu, S. (2013) Release of extracellular ATP by bacteria during growth. BMC. Microbiol. 13, 301- 314.

36. Guzel-Seydima, Z.B., Greeneb, A.K and Seydima, A.C. (2004) Use of ozone in the food industry. Food. Sci. Technol - LEB. 37, 453-460.

37. Cullen, P.J and Norton, T. (2012) Ozone sanitisation in the food industry in Ozone in Food Processing (O'Donnell, C., Tiwari, B.K., Cullen, P.J and Rice, R.G. Eds.) pp 163-176, Blackwell Publishing, Oxford.

38. Fielding, L.M., Hall, A and Peters, A.C. (2007) An evaluation of ozonated water as an alternative to chemical cleaning and sanitisation of beer lines. J. Foodservice. 18, 59-68.

39. Erriu, M., Blus, C., Szmukler-Moncler, S., Buogo, S., Levi, R., Barbato, G., Madonnaripa, D., Denotti, G., Piras, V and Orrù, G. (2014) Microbial biofilm modulation by ultrasound: Current concepts and controversies. Ultrason. Sonochem. 21, 15-22.

40. Patist, A and Bates, D. (2008) Ultrasonic innovations in the food industry: From the laboratory to commercial production. Innov. Food. Sci. Emerg. Technol. 9, 147-154.

41. Morikawa, T., Oka, K and Kojima, K. (1999) Fluidization and foam separation in brewing (III). Tech. Q. Master Brew. Assoc. Am. 33, 5458.

42. Storgårds, E., Yli-Juuti, P., Salo, S., Wirtanen, G and Haikara, A. (1999) Modern methods in process hygiene control - Benefits and limitations. Proc. Eur. Brew. Conv. Congr. Cannes, IRL Press, Oxford, pp. 249-258. 
43. Choi, E.J., Ahn, H., Kim, M., Han, H and Kim, W.J. (2015) Effect of ultrasonication on fermentation kinetics of beer using six-row barley cultivated in Korea. J. Inst. Brew. 121, 510-517.

44. Yaldagard, M., Mortazavi, S.A and Tabatabaie, F. (2008) Application of ultrasonic waves as a priming technique for accelerating and enhancing the germination of barley seed: Optimization of method by the Taguchi approach. J. Inst. Brew. 114, 14-21.

45. Clasen, T and Edmondson, P. (2006) Sodium dichloroisocyanurate (NaDCC) tablets as an alternative to sodium hypochlorite for the routine treatment of drinking water at the household level. Int. J. Hyg. Environ. Health. 209, 173-181.

46. Meyer, B. (2003) Approaches to prevention, removal and killing of biofilms. Int. Biodeterior. Biodegradation. 51, 249-253.

47. Morgenthau, A., Nicolae, A.M., Laursen, A.E., Foucher, D.A., Wolfaardt, G.M and Hausner, M. (2012) Assessment of the working range and effect of sodium dichloroisocyanurate on Pseudomonas aeruginosa biofilms and planktonic cells. Biofouling. 28, 111-120.

48. Schlisselberg, D.B and Yaron, S. (2013) The effects of stainless steel finish on Salmonella Typhimurium attachment, biofilm formation and sensitivity to chlorine. Food Microbiol. 35, 65-72.

Table 1. Microbiological loading (as colony-forming units) of the same brand of draught beer sampled in 12 on-trade accounts (numbered 1 to 12) and classified according to the DIN 6650 Part 6 standard (6) 


\begin{tabular}{|c|c|c|}
\hline $\mathrm{cfu} / \mathrm{ml}$ & Aerobes & Anaerobes \\
\hline$<1000$ & 11,12 & $5,6,7,10,11,12$ \\
\hline $1-10,000$ & $1,5,6,7$ & $1,3,4,8$ \\
\hline $10-50,000$ & $3,8,10$ & 2,9 \\
\hline$>50,000$ & $2,4,9$ & \\
\hline
\end{tabular}

Formatted: Font: Helvetica Formatted: Font: Helvetica Formatted: Font: Helvetica Formatted: Font: Helvetica Formatted: Font: Helvetica 
Table 2. Summary of different treatments on nozzle hygiene-mean bioluminescence ( \pm sem) and log reduction $v$ soda water

\begin{tabular}{|c|c|c|c|}
\hline Treatment & Figure & RLU \pm sem & Log reduction \\
\hline Soda water & $z$ & $250,796 \pm 27,115$ & - \\
\hline Ozonated water & $z$ & $271,428 \pm 93,857$ & - \\
\hline Soda water + ultrasonics (1 minute) & $z$ & $148 \pm 42$ & 3 \\
\hline Ozonated water + ultrasonics (1 minute) & $z$ & $66 \pm 8$ & 3 \\
\hline Soda water & 3 & $636,720 \pm 99,212$ & - \\
\hline Line-cleanef & 3 & $1,249 \pm 218$ & $z$ \\
\hline Sanitising tablets & 3 & $355 \pm 130$ & 3 \\
\hline Uttrasonies $(30$-seconds) & 3 & $40,925 \pm 13,872$ & - \\
\hline Uttrasonics (1 minute) & 3 & $34,806 \pm 11,822$ & - \\
\hline Uttrasonics ( 2 minutes) & 3 & $3,617 \pm 3,274$ & $z$ \\
\hline Ultrasonics (5 minutes) & 3 & $729 \pm 559$ & 3 \\
\hline Soda watef & 4 & $1,114,165 \pm 15,071$ & - \\
\hline Line-cleaner & 4 & $2,978 \pm 1,383$ & 10 \\
\hline Sanitising tablets & 4 & $123 \pm 61$ & 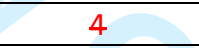 \\
\hline
\end{tabular}

Table 2. Overview of the preparation of microbial soup, cleaning treatments and analysis

\begin{tabular}{|c|c|c|c|c|c|}
\hline \multirow[t]{2}{*}{ Microbial soup } & \multicolumn{4}{|c|}{ Experimental approach } & \multirow[t]{2}{*}{ Analysis } \\
\hline & Nozzles & In beer (12h) & Treatments (12 h) & 24 h Cycles & \\
\hline 1. Beer ex dispense, & & & - Soda water & & \\
\hline $\begin{array}{l}\text { glucose, extended with } \\
\text { beer, and incubated for } \\
\text { seven days. Nozzles } \\
\text { added and incubated } \\
\text { for five days. }\end{array}$ & $\begin{array}{c}24 \\
\text { (six per } \\
\text { treatment) }\end{array}$ & $\checkmark$ & $\begin{array}{l}\text { Ozonated water } \\
\text { - Ultrasonics }(1 \mathrm{~min})+ \\
\text { soaked in soda water } \\
\text { - Ultrasonics }(1 \mathrm{~min})+ \\
\text { soaked in ozonated } \\
\text { water }\end{array}$ & 6 & $\begin{array}{c}\text { ATP } \\
\text { bioluminescence } \\
\text { Forcing (1 nozzle) }\end{array}$ \\
\hline
\end{tabular}

Formatted: Font: Helvetica, Bold

Formatted: Font: Helvetica

Formatted: Font: Helvetica

Formatted: Font: Helvetica

Formatted: Font: Helvetica

Formatted: Font: Helvetica 


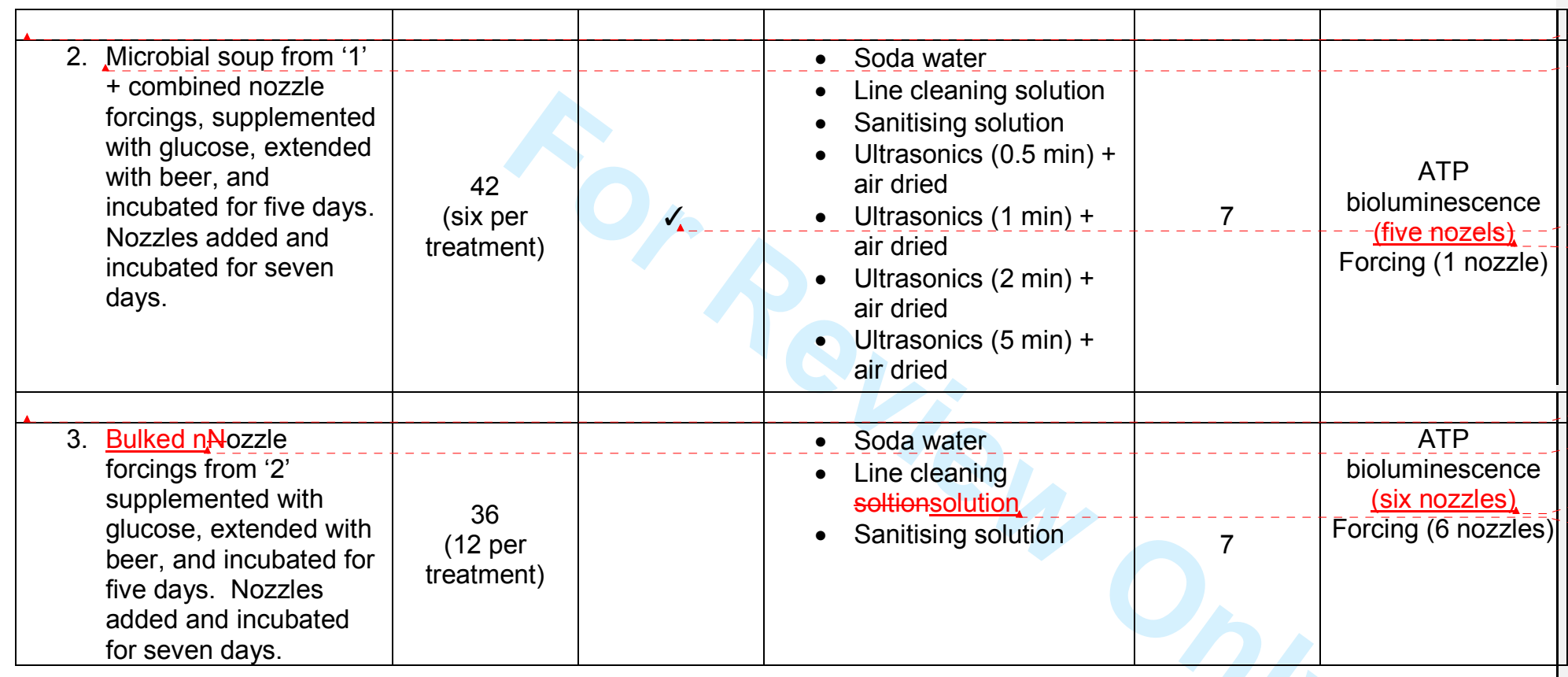

Formatted: Font: Helvetica

Formatted: Font: Helvetica

Formatted: Font: Helvetica

Formatted: Font: Helvetica

Formatted: Font: Helvetica

Formatted: Font: Helvetica

Formatted: Font: Helvetica

Formatted: Font: Helvetica 
Table 3. Summary of different treatments on nozzle hygiene - mean bioluminescence ( \pm sem) and log reduction $v$ soda water

\begin{tabular}{|l|c|c|c|}
\hline Treatment & Figure & RLU \pm sem & Log reduction \\
\hline Soda water & 2 & $250,796 \pm 27,115$ & - \\
\hline Ozonated water & 2 & $271,428 \pm 93,857$ & 3 \\
\hline Soda water + ultrasonics (1 minute) & 2 & $148 \pm 42$ & 3 \\
\hline Ozonated water + ultrasonics (1 minute) & 2 & $66 \pm 8$ & - \\
\hline Soda water & 3 & $636,720 \pm 99,212$ & 3 \\
\hline Line cleaner & 3 & $1,249 \pm 218$ & - \\
\hline Sanitising tablets & 3 & $355 \pm 130$ & - \\
\hline Ultrasonics (30 seconds) & 3 & $40,925 \pm 13,872$ & - \\
\hline Ultrasonics (1 minute) & 3 & $34,806 \pm 11,822$ & \\
\hline
\end{tabular}

Formatted: Font: Helvetica

\section{Formatted Table}

Formatted: Font: Helvetica

Formatted: Font: Helvetica

Formatted: Font: Helvetica

Formatted: Font: Helvetica

Formatted: Font: Helvetica

Formatted: Font: Helvetica

Formatted: Font: Helvetica

Formatted: Font: Helvetica

Formatted: Font: Helvetica 


\begin{tabular}{|l|c|c|c|}
\hline Ultrasonics (2 minutes) & 3 & $3,617 \pm 3,274$ & 2 \\
\hline Ultrasonics (5 minutes) & 3 & $729 \pm 559$ & 3 \\
\hline Soda water & 4 & $1,114,165 \pm 15,071$ & - \\
\hline Line cleaner & 4 & $2,978 \pm 1,383$ & 2 \\
\hline Sanitising tablets & 4 & $123 \pm 61$ & 4 \\
\hline
\end{tabular}

Formatted: Font: Helvetica

Formatted: Font: Helvetica

Formatted: Font: Helvetica

Formatted: Font: Helvetica

Formatted: Font: Helvetica 


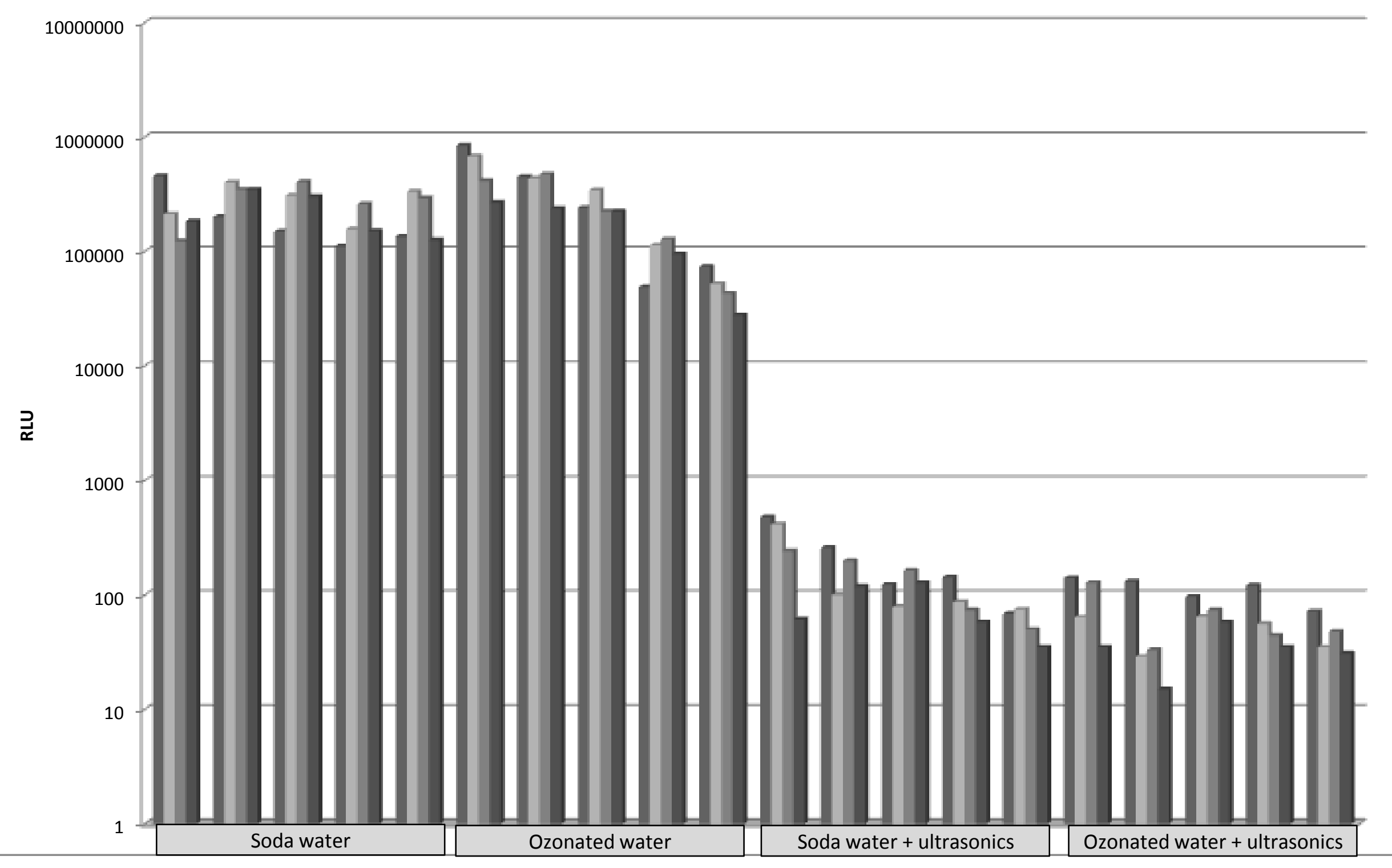




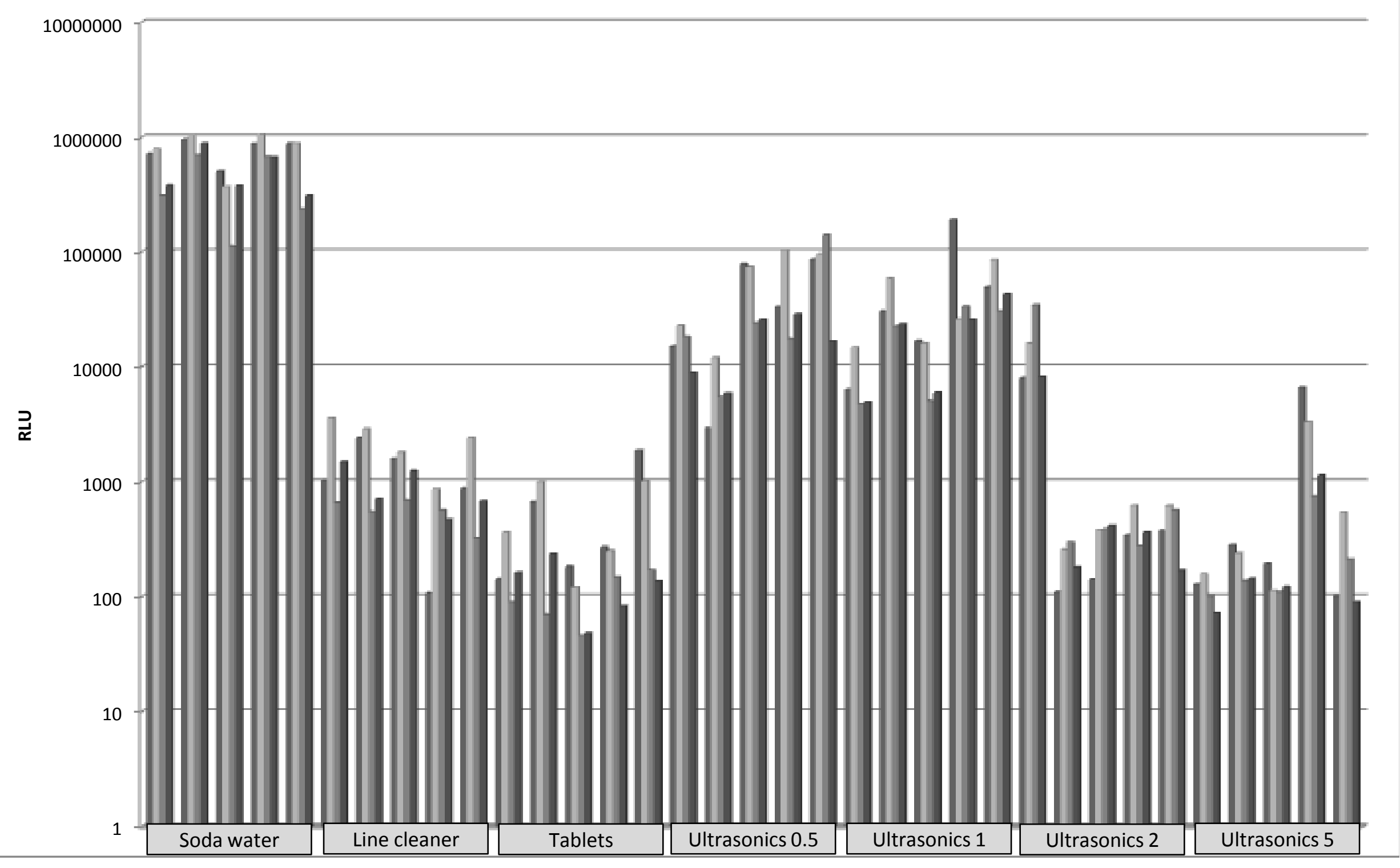




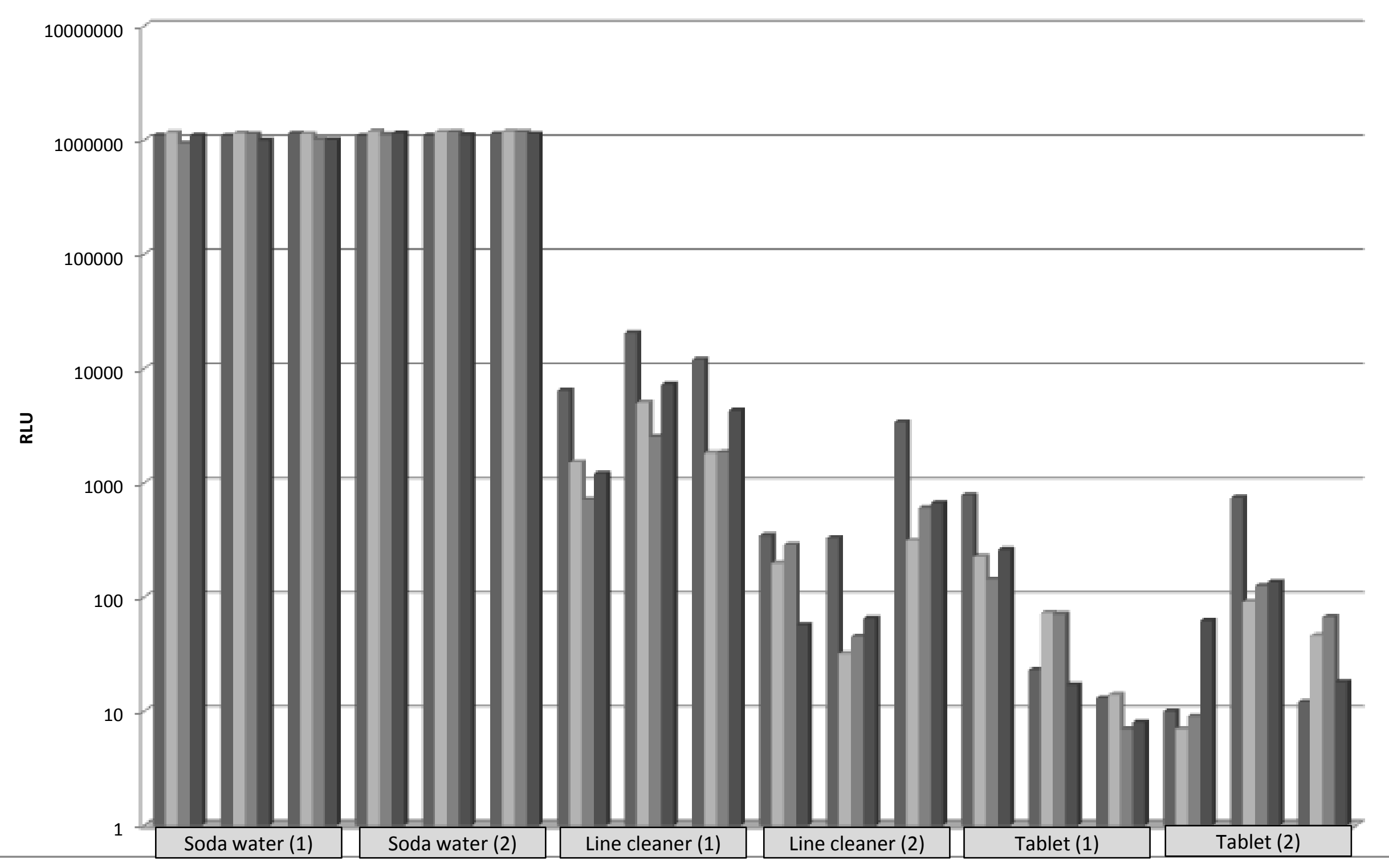




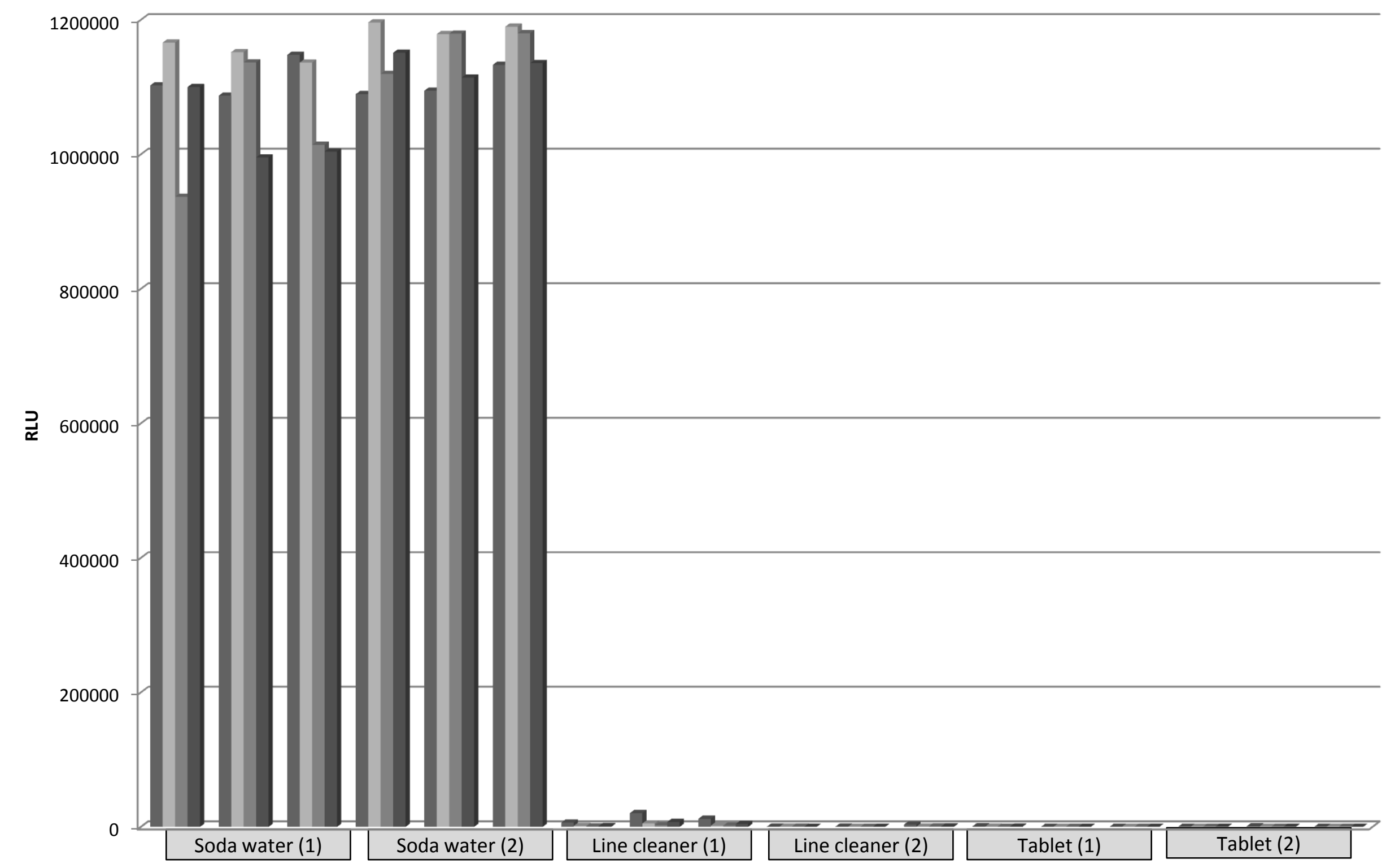




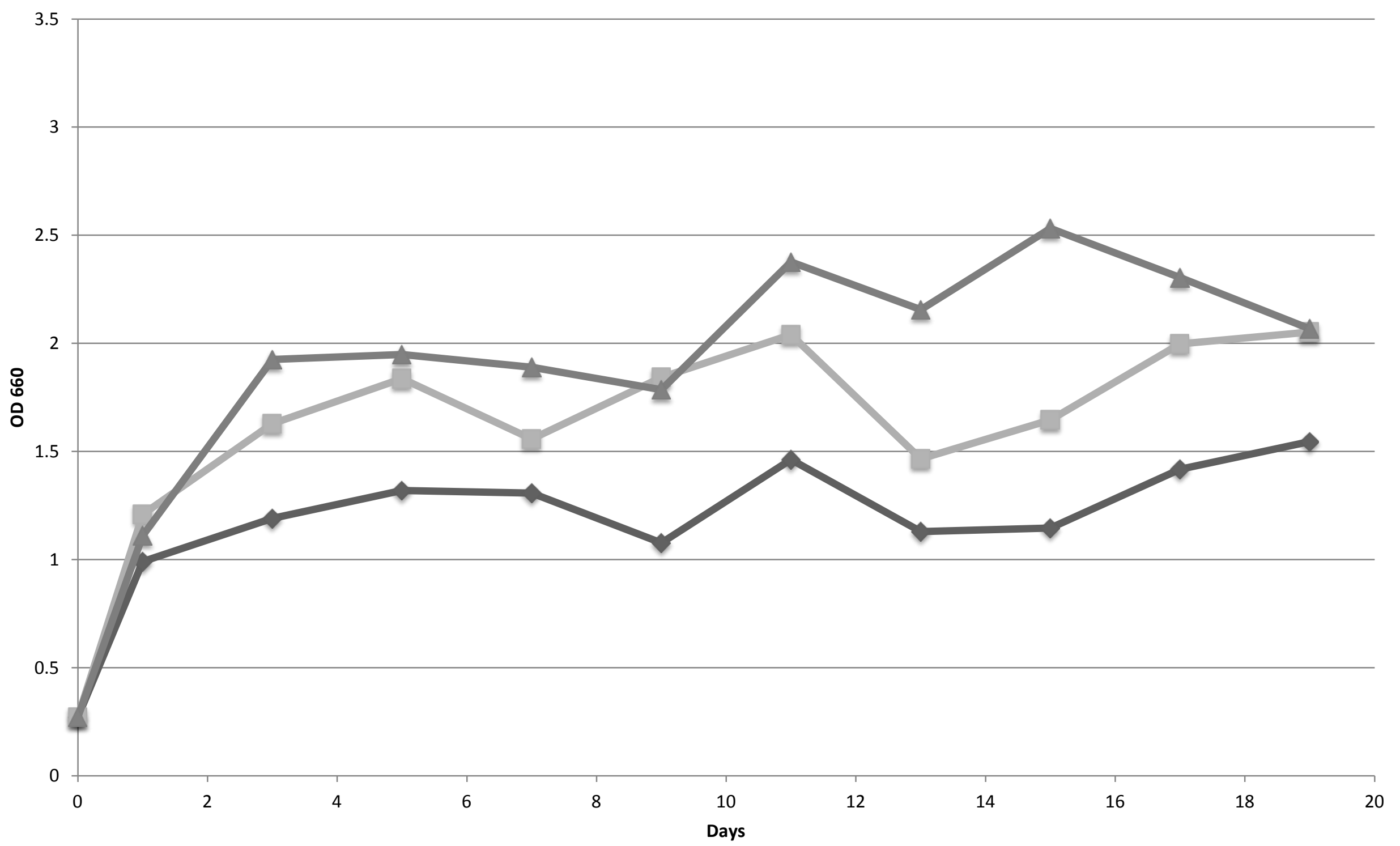




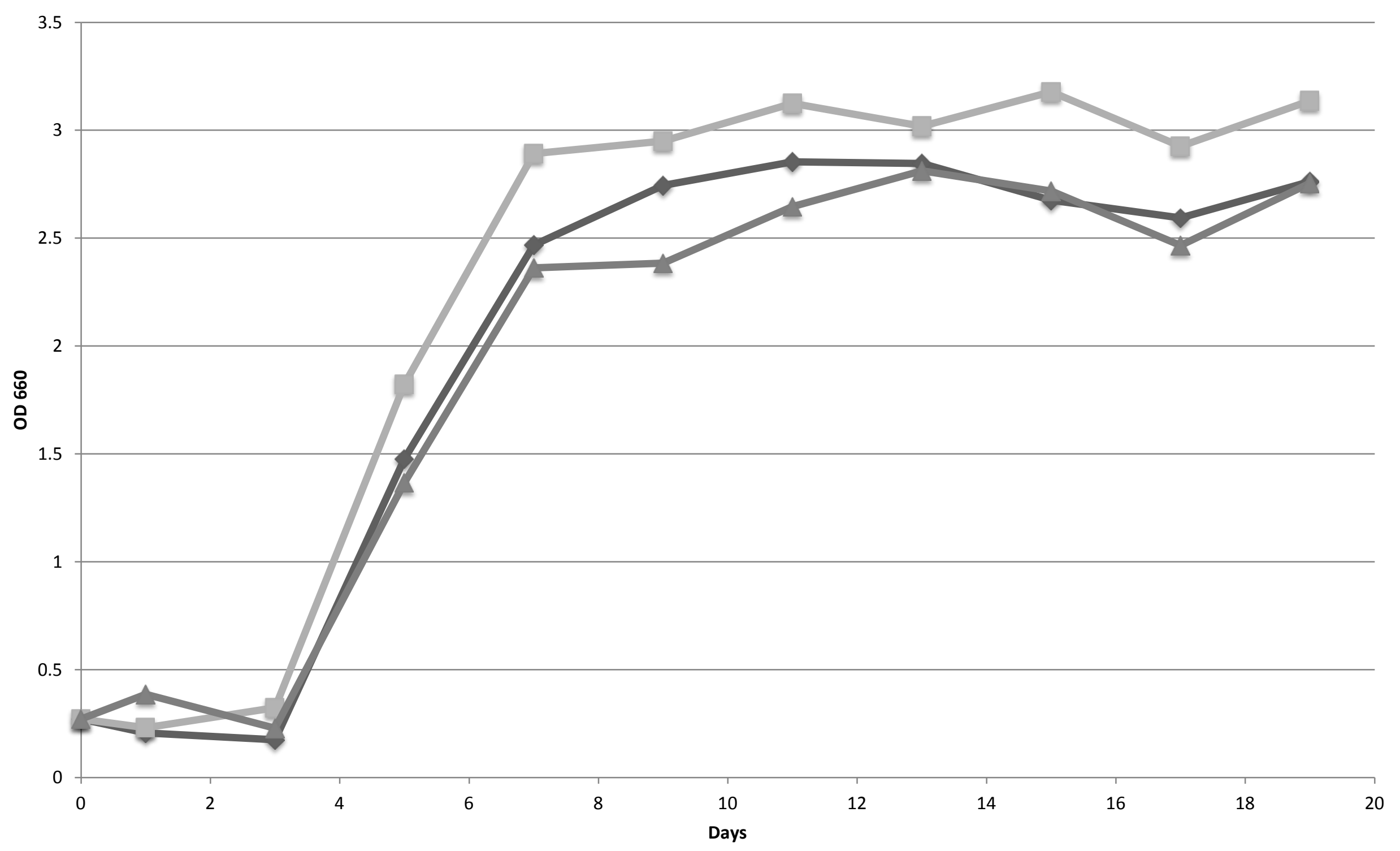




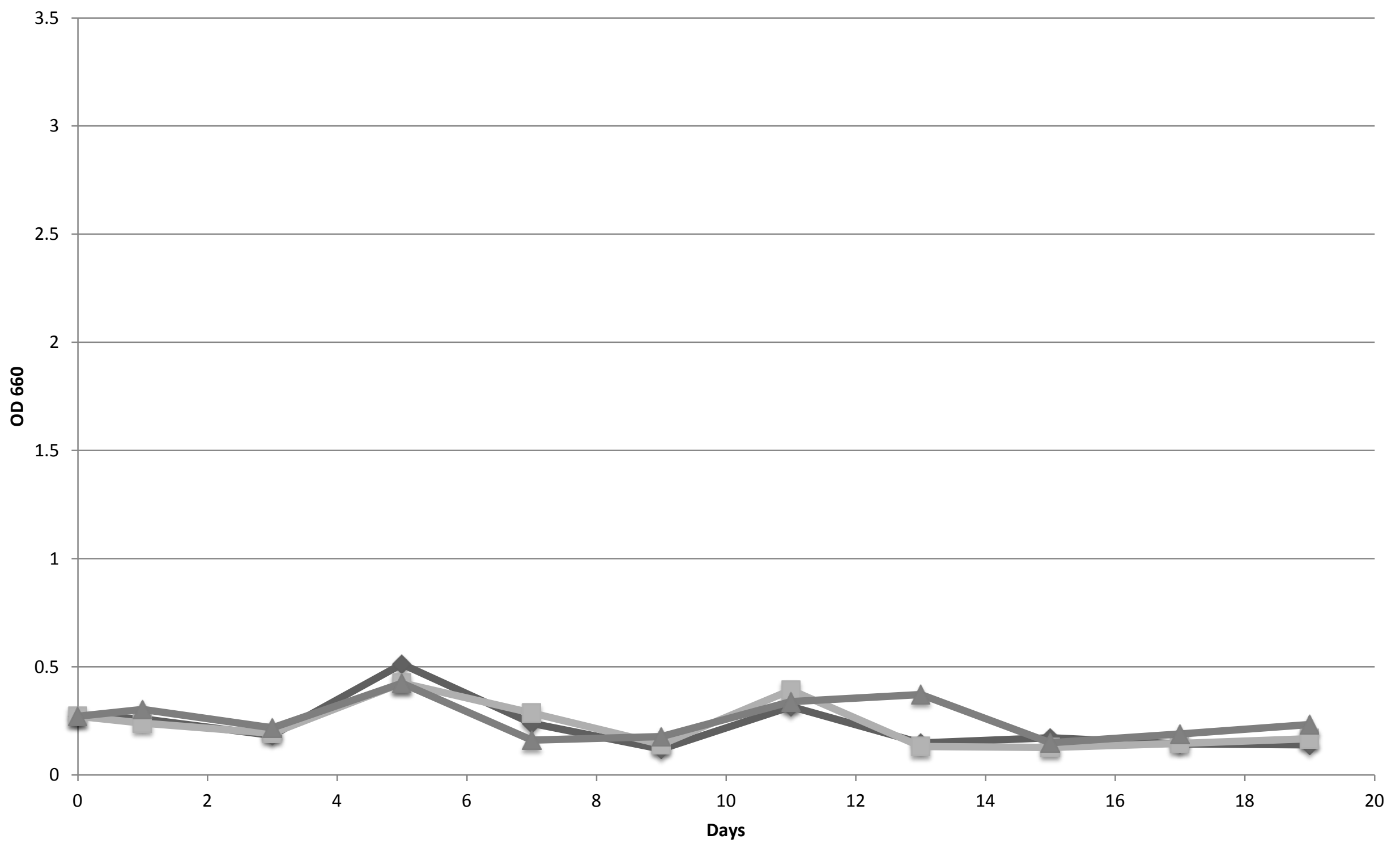

